\title{
Sustainable Development: A Vital Quest
}

\author{
Marc A. Rosen ${ }^{1 *}$ \\ ${ }^{1}$ University of Ontario Institute of Technology, CANADA \\ *Corresponding Author: marc.rosen@uoit.ca
}

Citation: Rosen, M.A. (2017) Sustainable Development: A Vital Quest, European Journal of Sustainable Development Research, 1:1 (2017), 2.

doi: http://dx.doi.org/10.20897/ejosdr.201702

Received: August 4, 2016; Accepted: August 20, 2016; Published: January 17, 2017

\begin{abstract}
A high-level overview of the discipline of sustainable development is presented, aimed at providing the context and setting for research on and applications of sustainable development, in this lead article to a new journal. The status of sustainable development and its progress are described, as are challenges and needs that may impact its development. Definitions of sustainable development and its interdisciplinary and multidisciplinary dimensions are discussed and contrasted with single-discipline approaches. Examples of interpretations and needs for sustainable development are provided from such fields as energy, resource management, and engineering. Attitudes towards sustainable development are investigated, as is progress. Finally, an illustrative case study is described of a large sustainable development initiative, comprised of several integrated measures and activities.
\end{abstract}

Keywords: sustainable development, environmental sustainable development, social sustainable development, economic sustainable development, sustainability

\section{INTRODUCTION}

Sustainable development is a rapidly growing, yet relatively new, discipline that is becoming increasingly applied in numerous areas, reflecting the desire of humanity to ensure the activities we undertake can be sustained into the future and do not adversely affect the environment and the ecological systems within it. In some ways, therefore, sustainable development is a vital quest for humanity, which is central to how we survive and thrive into the future.

Many factors affect the development and advancement of sustainable development, and some of these are shown in Figure 1. These factors include increasing clarity in what is meant by definitions of sustainable development, in hopes of achieving a universal understanding of what sustainable development means. Also, the multidisciplinary nature of sustainable development is becoming an increasing driver of sustainable development efforts, although the need for disciplinary-specific illustrations and applications of sustainable development are also seen to be important. The attitudes of people and communities towards sustainable development remain an important factor in the advancement of sustainable development, in that it is difficult to move forward when people and communities are not supportive of sustainable development and the ideas embodied within it. The needs of people are an important factor in sustainable development initiatives, especially in developing and poorer countries. Finally, progress in the ideas, systems and technologies that facilitate sustainable development are a very significant factor, as such progress increases the array of tools that can be employed. Many of these factors are examined further this article, where needed to provide deeper insights and illustrations.

In this article, the status of sustainable development and its progress are described, and issues and barriers that may impact its further advancement are examined. Definitions of sustainable development are described and its interdisciplinary and multidisciplinary dimensions are investigated, and contrasted with single-discipline approaches. Several examples of interpretations and needs for sustainable development are provided. These 


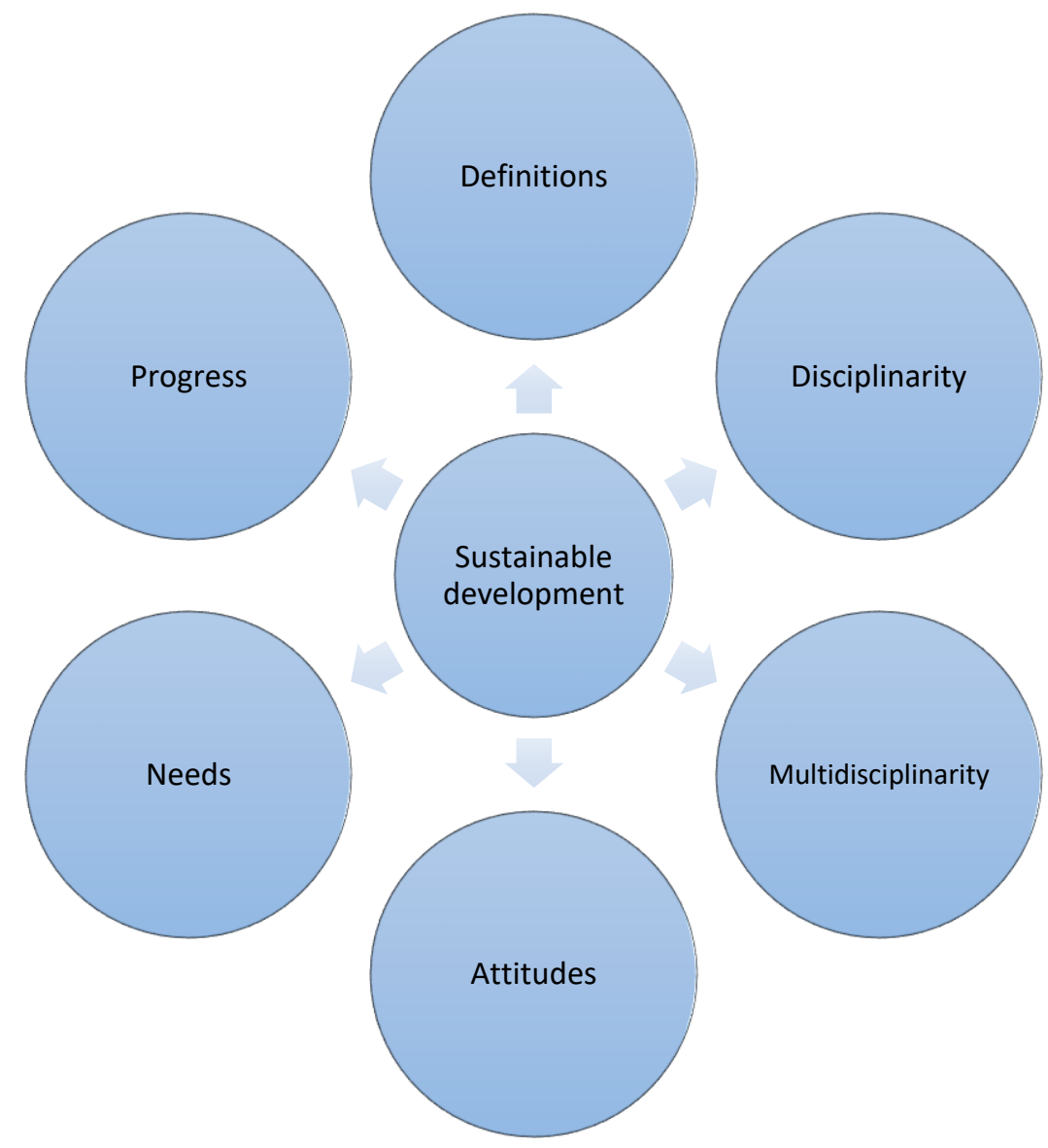

Figure 1. Some of the many factors affecting the advancement of sustainable development.

examples cover a range of important fields: energy, resource management, and engineering. Attitudes towards sustainable development are investigated, as are needs and progress. Finally, a case study of a large sustainable development initiative, made up of several integrated measures and activities, is described to illustrate the concepts raised in the article and to further highlight why sustainable development is a vital quest for humanity.

This article constitutes the lead article in a new journal and, as such, has the objective of providing a high-level overview of the discipline of sustainable development. Beyond introducing the discipline, this article is intended to help provide the context and setting for the many articles that follow.

\section{DEFINITION}

Sustainable development is difficult to define precisely, and consequently many definitions for it exist and are used. Often the definitions are specific to the areas in which the word is employed, e.g., business sustainable development speaks to the ability of businesses to survive and thrive over the long term, while environmental sustainable development is concerned with protecting the environment and its ecology well into the future. Nonetheless, many common characteristics and features emanate from these definitions.

Many facets of the term sustainable development are embodied in the definition put forth by the World Commission on Environment and Development (i.e., the Brundtland Commission) in 1987. It defined sustainable development as

\section{"development that meets the needs of the present without compromising the ability of future generations to meet their own needs."}

Some define sustainable development as the simultaneous achievement of activity in the environmental, economic and social spheres that can be carried on into the future without undue harm in any of these areas.

Other attempts have been made to define what is meant by sustainable development, what efforts to achieve it require, and how it can be measured and monitored. Clarity in these is needed for sustainable development to be incorporated in the activities that people and societies undertake. 


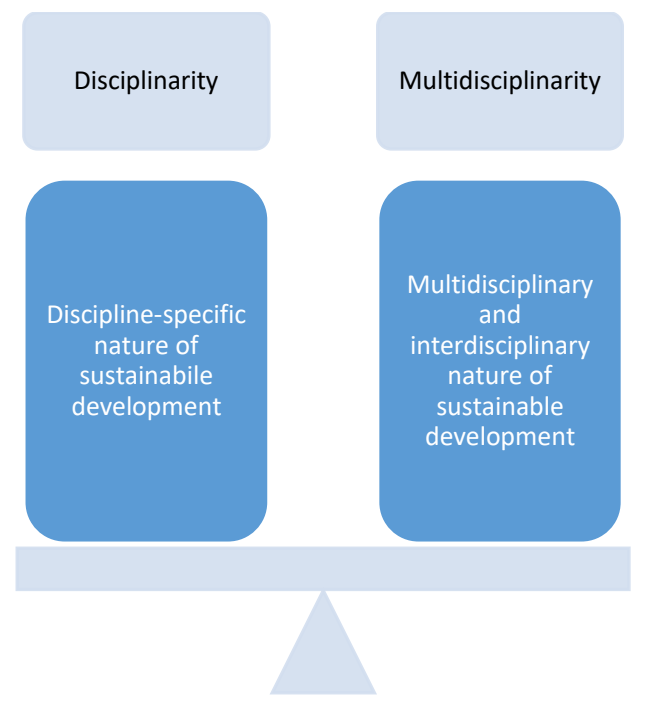

Figure 2. Illustration of the need for a balance between the single disciplinary and multidisciplinary and interdisciplinary natures of sustainable development

\section{Sustainable development}
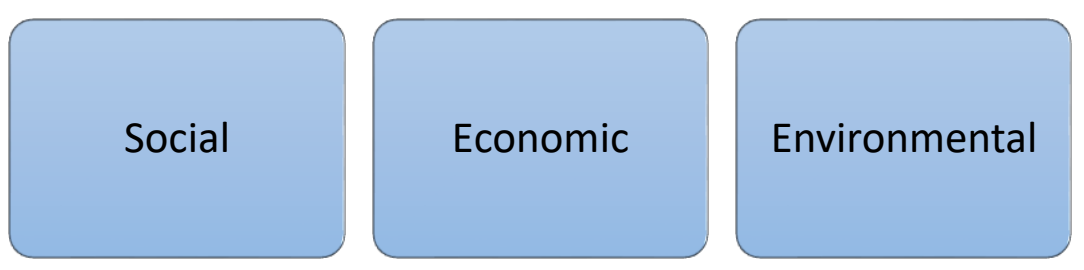

Figure 3. Illustration of relations between primary sustainable development dimensions, in which sustainable development is supported by pillars representing environmental, economic and social sustainable development, and can only remain standing if an appropriate balance is achieved among the often-conflicting requirements for environmental, economic and social sustainable development

Despite the differences in definitions, the common themes in them permit an increasingly clear understanding of the concept of sustainable development to be attained

\section{DISCIPLINARY VS. MULTIDISCIPLINARY}

The manner in which sustainable development is employed often varies with the field of application, often making it seem quite discipline specific. The term may be used with specific meanings by philosophers, political scientists, sociologists, ethicists, economists, geographers, biologists, ecologists, and engineers. Sometimes these meanings differ yet at other times they overlap and exhibit commonalities. These commonalities often suggest sustainable development has a multidisciplinary and interdisciplinary nature. The single disciplinary and multidisciplinary natures of sustainable development are illustrated in Figure 2, where a balance is shown to be needed between the two.

When viewed as multidisciplinary, the character of sustainable development becomes astonishingly diverse. It has implications affecting fields as diverse as science, engineering, environment, ecology, economics, business, sociology, philosophy, and others. This breadth is not surprising, given that sustainable development has been for some years identified as having environmental, economic, social and cultural dimensions.

The ways in which these sustainable development dimensions link can be illustrated in many ways. In Figure 3 , for instance, sustainable development is seen to be founded or supported by three pillars or legs (representing environmental, economic and social sustainable development, somewhat like a three-legged table. The table can only remain standing, or sustainable development can only be achieved, if the requirements for each of 


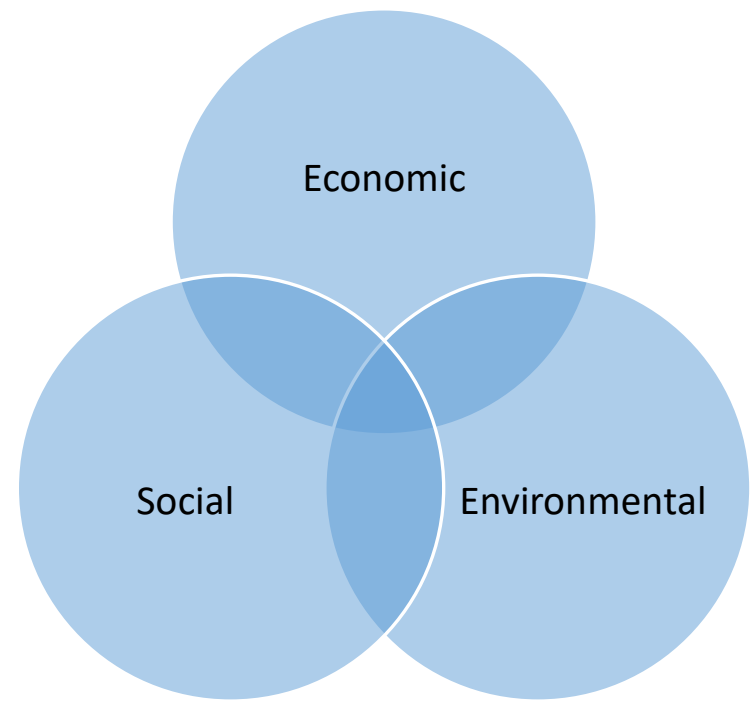

Figure 4. Illustration of relations between primary sustainable development dimensions, in which sustainable development is represented as the common intersection of the three spheres of environmental, economic and social sustainable development.

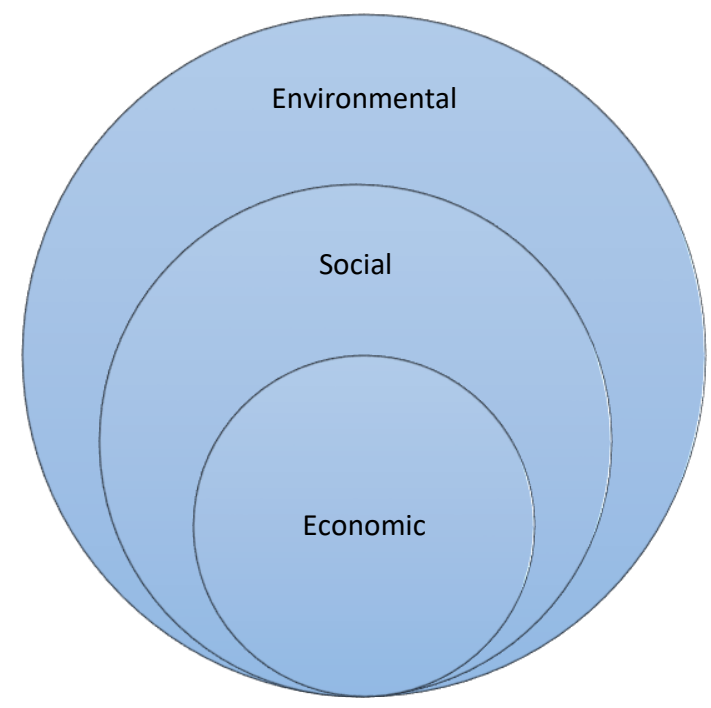

Figure 5. Illustration of relations between primary sustainable development dimensions, in which achieving environmental sustainable development is shown to require social sustainable development since the environment includes elements of society as well as other dimensions (e.g., ecological systems), while achieving social sustainable development is shown to require economic sustainable development since society includes elements of elements of economics and industry as well as other dimensions (e.g., cultural systems).

environmental, economic and social sustainable development are satisfied). The can prove a difficult balancing act, as these sustainable development dimensions are often in conflict. In Figure 4, sustainable development is represented as the common point of overlap of three intersecting circles, where the three circles represent respectively the environmental, economic and social dimensions of sustainable development. A variation on this representation is provided in Figure 5, where sustainable development is represented as concentric circles. Economic sustainable development, being an activity of people and occurring within communities, is seen to be a subset of social sustainable development, which involves a myriad of social and cultural dimensions as well as economic factors. Then social sustainable development is seen to be a subset of environmental sustainable development, since everything that is done by people and societies is carried out within the environment and thus poses a threat to environmental sustainable development. Despite their differences, all of these interpretations and illustrations of sustainable development are related conceptually and share important linkages.

Addressing sustainable development requires that we consider needs for resources, economic, cultural and social development, health, environmental impact, engineering, design and architecture, as well as an understanding of how people interact and relate with respect to these topics. 
The breadth of areas subsumed by sustainable development is being seen as increasingly broad. It includes such a wide - and sometimes seemingly unending range of issues - including but not limited to:

- Industrial development, including production and consumption patterns, and supply chains.

- Resources supplies, including energy, minerals, water and other materials.

- Environmental protection, including pollution control, waste management, and climate change mitigation and adaptation, and natural disasters.

- Ecosystem degradation, including species extinction and loss of biodiversity, declining water quality, and drought,

- Appropriate consideration of land use, including deforestation, loss of arable land, sanitation and desertification.

- Population growth and distribution, including urbanization and globalization issues.

- Social and cultural factors, including living standards,

- Societal stability, including peace and anthropogenic disasters.

- Government influences, including policies, incentives and disincentives.

\section{EXAMPLES}

\section{Energy and resource sustainable development}

First consider energy and other resources as an example. The most important resources usually are taken to include energy, materials and water. We examine energy sustainable development here, as well as the broader concept of resource sustainable development.

The achievement of energy sustainable development is an enormous challenge. Energy resources are important and drive much of the global economy, while contributing to good living standards. But most countries are dependent on non-sustainable energy resources, particularly fossil fuels. These are finite in nature and contribute significantly to environmental impacts like climate change.

Consequently, efforts are needed to develop of sustainable energy systems. These must enhance the viability and increase the adoption of sustainable energy resources, like solar, geothermal, tidal, and wind energy. Efforts are also needed to improve processes for producing energy carriers like hydrogen that facilitate their use. Sustainable energy systems also necessitate improved usage of energy resources to satisfy needs, and greater efficiency through such modern techniques as exergy analysis (Dincer and Rosen, 2013; Zvolinschi et al., 2007).

Similarly, as well as more broadly and generally, supplying global needs for materials and fresh water has become a major challenge, societies and policy makers, as well as for engineers and scientists. Like energy, materials and fresh water are key resources for modern societies and many issues relating to sustainable development stem from problems related to their supply and use.

Enhanced economic and environmental performance is also needed for sustainable systems for energy, materials and fresh water resources, as are efforts to address issues like population growth, increasing affluence in many countries and the corresponding increased consumption of energy, materials and fresh water. Contributions in these areas can lead to resource sustainable development which in turn supports the achievement of overall sustainable development.

An illustration of the needs for energy sustainable development, developed by the author from a holistic perspective but with a technical focus, is presented in Figure 6.

\section{Engineering sustainable development}

As another example, consider the need for sustainable development in engineering. Engineering constitutes the application of scientific and mathematical principles for practical purposes such as the design, manufacture, and operation of products and processes, while accounting for constraints related to economics, the environment and other sociological conditions. Engineering activities are significant contributors to economic development, standards of living and well-being of a society, and impact its cultural development and environment. Technical advances are continually developed through engineering. Many factors need to be considered and appropriately addressed in moving towards engineering sustainable development. They include appropriate selection of resources bearing in mind sustainable development criteria, the use of sustainable engineering processes, enhancement of the efficiency of engineering processes and resource use, and a holistic adoption of environmental stewardship in engineering activities. In moving towards engineering sustainable development, other key sustainable development measures also need to be addressed, such as economics, equity, land use, lifestyle, sociopolitical factors and population. 


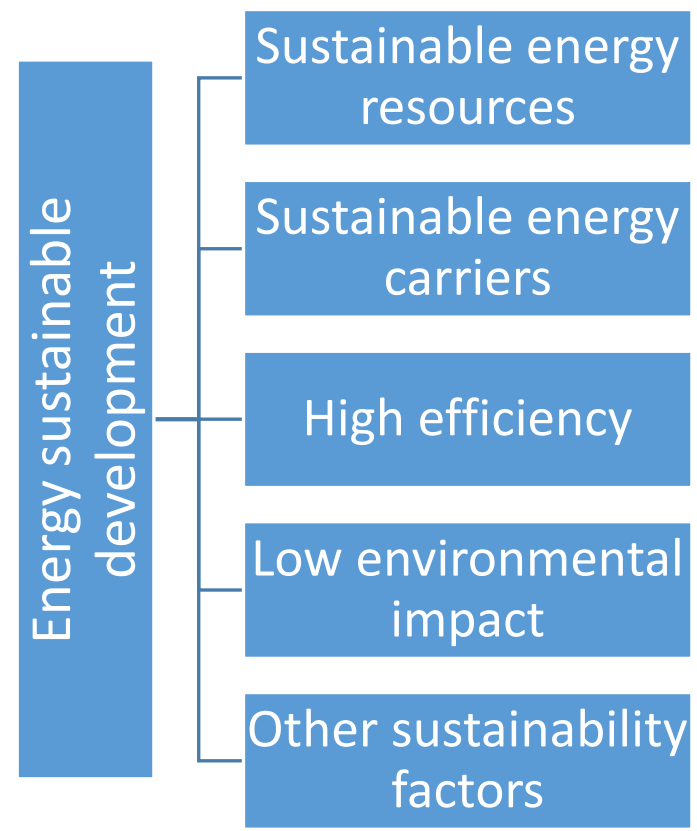

Figure 6. Requirements for energy sustainable development. The final box on the right includes many factors, including economics, social and cultural acceptability, lifestyles and living standards.

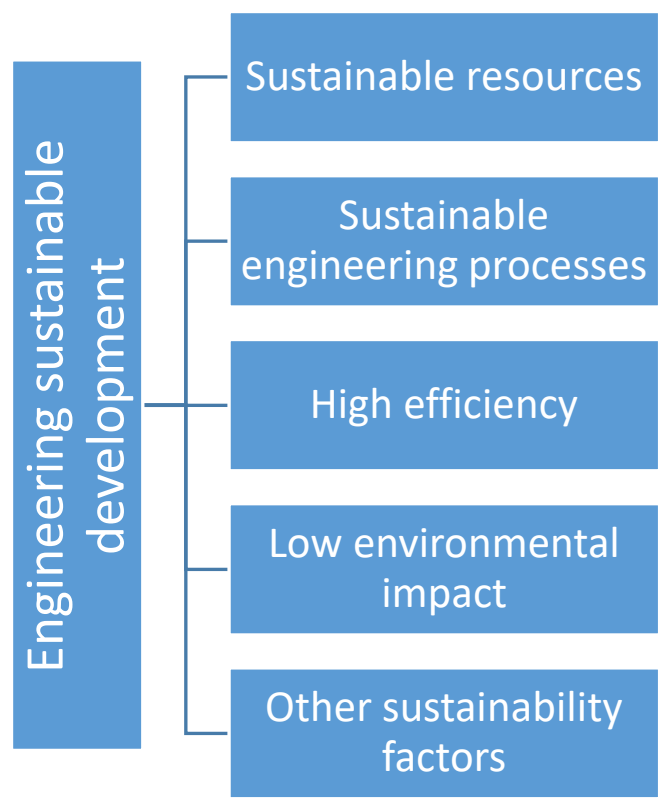

Figure 7. Requirements for engineering sustainable development. The final box on the right includes many factors, including economics, social and cultural acceptability, lifestyles and living standards

An illustration of the needs for engineering sustainable development, developed by the author from a holistic perspective but with a technical focus, is presented in Figure 7. It is informative to compare and contrast Figure 7 with the similar figure for energy sustainable development presented earlier (see Figure 6). It is noted that the figures are similar, but exhibit some important differences. The first two factors in each diagram differ, although both focus on resources. The energy sustainable development diagram is concerned with sustainable energy resources, while the engineering sustainable development diagram is broader, covering sustainable resources of all types, including but not limited to, energy resources. The second factor on the right of the energy sustainable development diagram focuses on energy carriers, which is a somewhat unique factor lined to energy systems, while the second factor of the engineering sustainable development diagram focuses on sustainable engineering processes, regardless of field (e.g., manufacturing, chemical processing, mining). The last three factors on the right side of each diagram are the same. This reflects the common requirement for reasonably high efficiency, low environmental and ecological intrusiveness and addressing of other sustainable development factors like economics and social factors. 


\section{Sample applications}

The sustainable nature of various types of technology have been examined over the decades. Dewulf et al. (2000) quantified the sustainability of technology via a range of illustrations.

Sustainable development and its relation to energy, water and environment systems are being investigated by many researchers. For instance, Krajacic et al. (2015) provide an overview of this topic, drawing from numerous investigations into sustainable development in the fields of energy, water and the environment.

Many energy systems have been developed to improve sustainable development. For instance, GomezEcheverri et al. (2012) led an extensive global energy assessment aimed at identifying routes to a sustainable future. Hacatoglu et al. $(2015,2016)$ report sustainability assessments of energy systems in general, and a wind-hydrogen energy system in particular. In the latter case, they contrast and compare that technology based on sustainability with a conventional gas-fired system. Also, Gnanapragasam et al. (2011) investigated the sustainability of an energy conversion system in a country involving large-scale integrated hydrogen production using solid fuels, while Evans et al. (2009) assessed sustainability indicators for renewable energy technologies.

Infrastructure and buildings, and related energy and water systems, have also been examined on the basis of sustainable development. For example, Russell-Smith et al. (2015) have soutght to improve building energy and environmental performance using sustainable target value design. Furthermore, Khalid et al. (2015) have developed and analyzed sustainable building HVAC applications.

Manufacturing activities have also been examined in terms of sustainable development. Sustainability has been examined as a tool for manufacturing decision making and development by Nazzal et al. (2013).

Broader studies of sustainable development for regions have been undertaken. For example, Ali Mansoori et al. (2016) have examined sustainable development for a single state, while some have examined a country (Gnanapragasam et al., 2011) and others the world (Gomez-Echeverri et al., 2012).

\section{ATTITUDES}

Much research has been reported relating to attitudes and actions regarding sustainable development. For instance, some have sought to understand and define sustainability and sustainable development, while others have examined the sudden and incremental changes associated with shifting towards sustainable development. Many have questioned the merits of the concept and its applications. Education efforts to improve attitudes, views and actions in relation to sustainable development have been made, especially focused on youth.

The attitudes towards sustainable development have been examined in many constituencies, including business, the public, students, and scientists and engineers. As an example, we consider here the latter constituency, engineers. The present author recently examined the attitudes and actions of engineering practitioners in terms of sustainability (Rosen, 2013).

In recent years, there has been a growing focus on and implementation of sustainable development measures in engineering, and attitudes of engineers towards sustainable development have been reported as becoming more positive. As evidence of this, an extensive survey of engineers and engineering students was undertaken recently, and observed to suggest that there is a strong focus on the implementation of sustainable development concepts, actions and measures in engineering. The online survey questioned members of the American Society of Mechanical Engineers about sustainability trends in mechanical engineering and manufacturing, and on how mechanical engineers and manufacturers are practicing green design, and its intent was to try to understand the views and actions of engineers and their companies about the concept of sustainability.

For example, a breakdown of the degree of involvement of engineers with sustainable development or sustainable technologies, based on the survey results (Rosen, 2013), is shown in. Figure 8. It is observed that more than two-thirds of engineers are involved to some degree in sustainability. This means typically that about twothirds of practicing engineers have worked on sustainable products and processes.

Also, the factors most likely to influence an organization's use of green design practices and procedures, and the frequency with which they are cited by respondents of the survey (Rosen, 2013), are shown in Figure 9. The dominant factors are found in the survey to be regulatory requirements (at over $40 \%$ ), followed by client demand and rising energy costs (both slightly under $20 \%$ ).

Some other specific interesting findings of that study follow:

- The main sustainable technology priorities are using less energy and natural resources, reducing emissions and material wastes, and utilizing renewable, recyclable and recycled materials.

- Over half of engineering students are involved with sustainable design in their studies.

- Sustainable engineering within organizations is mainly driven by regulatory requirements, rising energy costs and client demand, but challenges to sustainable engineering like economics need to be addressed to increase the incorporation of sustainable development in engineering. 


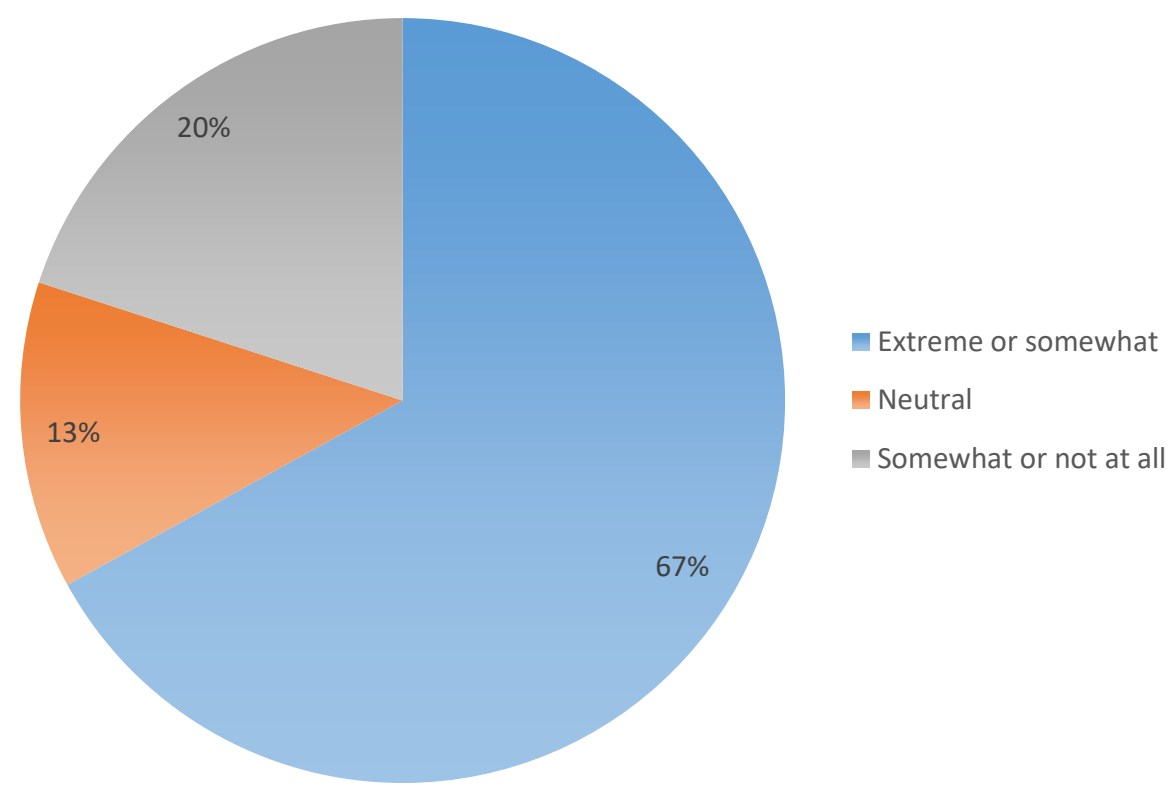

Figure 8. Degree of involvement of engineers with sustainability or sustainable technologies, based on a survey of practicing engineers of all ages and levels of experience mainly in areas related to mechanical engineering

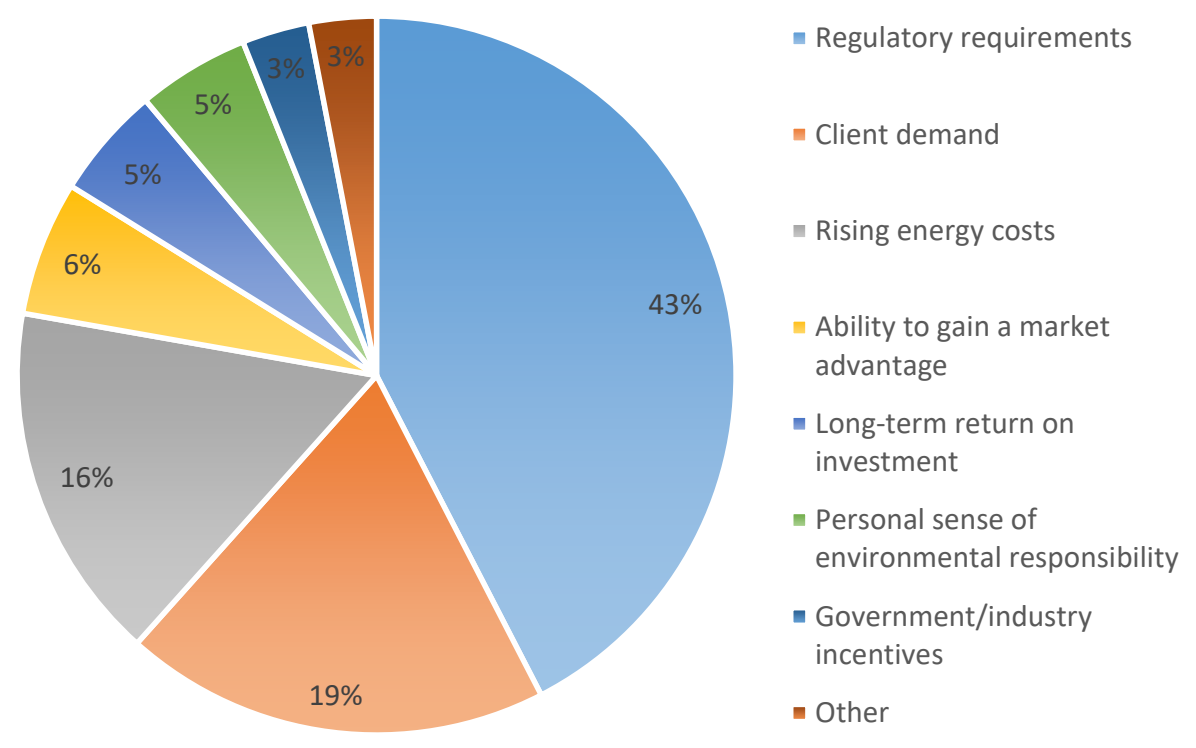

Figure 9. Factors most likely to influence an organization's use of green design practices and procedures, based on a survey of practicing engineers of all ages and levels of experience mainly in areas related to mechanical engineering

The survey consequently suggests that there is a strong focus on the implementation of sustainable development and sustainability concepts, actions and measures in engineering, by both individual engineers and engineering corporations.

\section{NEEDS AND PROGRESS}

Notwithstanding the growing interest in sustainable development and sustainability, and despite the need for better understanding and application of the principles of sustainable development, new achievements and advances are required in sustainable development and sustainability. This is not particularly surprising given that, in many ways, the field is still in its infancy.

Questions and uncertainties exist that necessitate the development of comprehensive approaches and methods for dealing with sustainable development. Where possible, these require widespread or universal support and 
adoption, to allow the discipline of sustainable development to advance in a coordinated fashion. Yet at the same time such approaches and methods require the flexibility and robustness necessary to permit discipline and application specific issues to be addressed.

Research is needed to guide the advancement of appropriate sustainable development measures and indicators, which are meaningful, useful and practical, to help assess and monitor the impacts of sustainable development efforts, and to help in setting targets or goals for such efforts. For instance, Zvolinschi et al. (2007) proposed sustainability indicators, with a focus on industrial ecology. An assessment of sustainability indicators for renewable energy technologies was performed (Evans et al., 2009), and Frangopoulos and Keramioti (2010) carried out multicriteria evaluations of energy systems accounting for sustainability considerations. Also, a new model to assess the environmental impact and sustainability was proposed by Hacatoglu et al. (2015), who also developed a novel sustainability assessment index for assessing and comparing technologies and approaches has (Hacatoglu et al. 2016). Life cycle assessment has been integrated with target value design to attain a methodology known as sustainable target value design (Russell-Smith et al., 2015). An identification key has been proposed for selecting methods for sustainability assessments (Zijp et al., 2015). Earlier, efforts were also put forth to quantify the sustainability of technology (Dewulf et al., 2000).

Efforts are being expended on innovation related to or for sustainable development. Much of this work was recently reviewed by Adams et al. (2016), who systematically examined research into sustainable developmentoriented innovation.

More broadly, efforts are needed to develop coordinated strategies and policies that are both soundly based and realistic.

Some believe that there is a need for a dedicated discipline like sustainable development science or sustainable engineering, to provide a focal point for developments in sustainable development, regardless of application area. For example, efforts have been made to develop sustainability science, by determine if a theory of social choice is possible (Anderson et al., 2016).

All such efforts need to simultaneously take a multidisciplinary approach - accounting for and reflecting the environmental, economic and societal pillars of sustainable development and also accounting for technical and other pertinent factors - and ensure applicability to many if not all discipline-specific applications. Satisfying these needs may be challenging, but are likely prerequisites to sustainable development being incorporated more extensively and widely into the activities of industry, the actions of government, the directions of society and the lives of people.

Irrespective of the needs for developments and advances in the field of sustainable development, progress and advances are being made.

At the political level, the UN Millennium Development Goals (MDGs), which encompassed many sustainable development concepts, were adopted by the international community in the year 2000 for a 15 -year period. Many positive accomplishments resulted from efforts associated with the goals. For instance, in most countries, rates of infant, child and maternal mortality have declined, extreme poverty and hunger have been reduced, access has improved to safe drinking water and sanitation, better availability has been attained for girls to better to primary schooling, and progress has been made in slowing the spread of HIV/AIDS and tuberculosis. However, not all goals have been achieved and some regions have benefitted less, particularly Sub-Saharan Africa and Southeast Asia.

As a follow up to the UN Millennium Development Goals, world leaders adopted the 2030 Agenda for Sustainable Development, which includes a set of 17 Sustainable Development Goals (SDGs), at the 70th Session of the UN General Assembly in 2015. The goals aim to end poverty, combat inequality and injustice, and address climate change by 2030, among other objectives. The 17 specific sustainable development goals are illustrated in Figure 10, and can be described as follows:

1. End poverty in all its forms everywhere

2. End hunger, achieve food security and improved nutrition and promote sustainable agriculture

3. Ensure healthy lives and promote well-being for all at all ages

4. Ensure inclusive and equitable quality education and promote lifelong learning opportunities for all

5. Achieve gender equality and empower all women and girls

6. Ensure availability and sustainable management of water and sanitation for all

7. Ensure access to affordable, reliable, sustainable and modern energy for all

8. Promote sustained, inclusive and sustainable economic growth, full and productive employment and decent work for all

9. Build resilient infrastructure, promote inclusive and sustainable industrialization and foster innovation

10. Reduce inequality within and among countries

11. Make cities and human settlements inclusive, safe, resilient and sustainable 


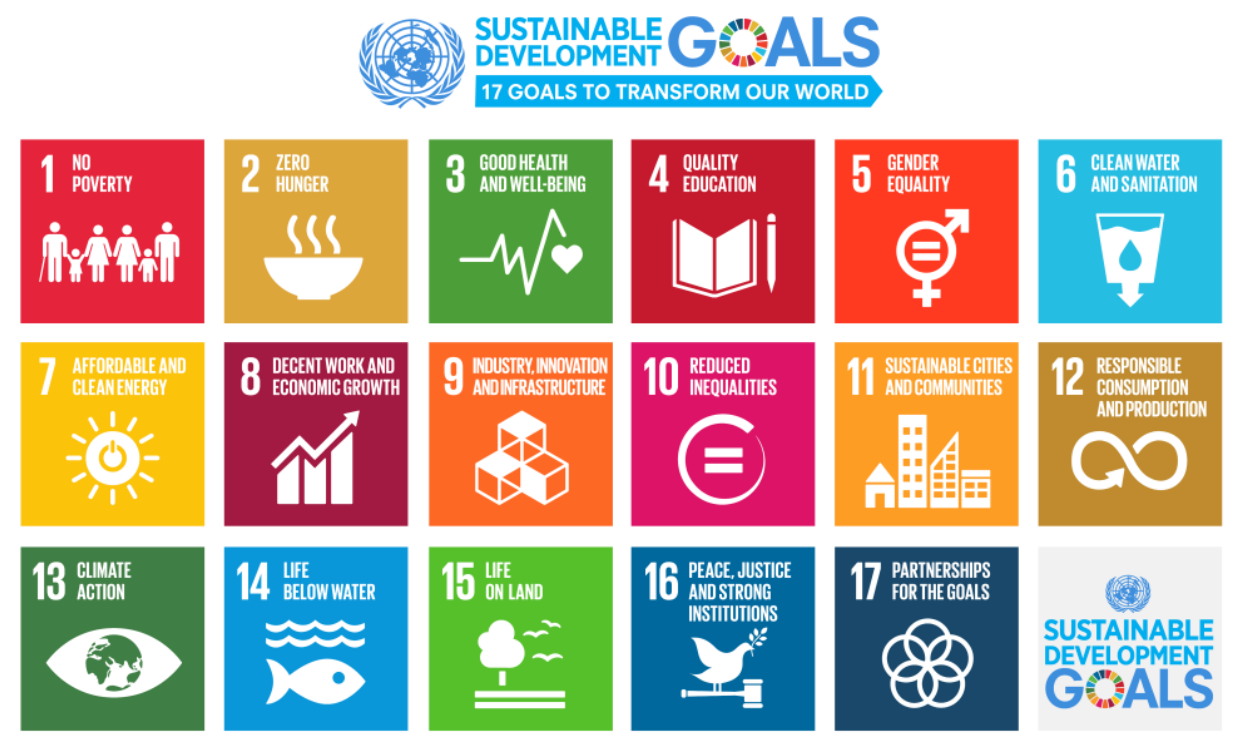

Figure 10. Sustainable Development Goals adopted at the 70th Session of the UN General Assembly in 2015 (public domain material provided by United Nations at http://www.un.org/sustainabledevelopment/news/communications-material/)

12. Ensure sustainable consumption and production patterns

13. Take urgent action to combat climate change and its impacts*

14. Conserve and sustainably use the oceans, seas and marine resources for sustainable development

15. Protect, restore and promote sustainable use of terrestrial ecosystems, sustainably manage forests, combat desertification, and halt and reverse land degradation and halt biodiversity loss

16. Promote peaceful and inclusive societies for sustainable development, provide access to justice for all and build effective, accountable and inclusive institutions at all levels

17. Strengthen the means of implementation and revitalize the global partnership for sustainable development

This new set of goals are similar in some respects to the UN Millennium Development Goals but they also extend them significantly. For instance, the formulation and focus of the UN Sustainable Development Goals are more encompassing and require active participation from wealthy and poor nations alike, and the overall focus has shifted to improving the sustainability of global economic and social development while protecting the environment, from improving the situation of poor and underdeveloped regions and societies.

Progress and advances have also been made by researchers focusing on sustainable development, suggesting a bright future for the field of sustainable development especially when viewed with the political and societal advances being made. Numerous approaches to investigating sustainable development and sustainability have been put forward from many perspectives, including social, economic, environmental and technical. Some interesting examples follow:

- The types of socio-economic approaches being taken include modifying lifestyles; investigating the impact of sustainable development on cultural diversity, social systems, globalization and immigration patterns; the provision of sustainable development education and raising awareness and appreciation of it; approaching sustainable development and sustainability from ethical and philosophical perspectives, developing national policies for sustainable development and sustainability; and creating international agreements like the UN 2030 Agenda for Sustainable Development and its Sustainable Development Goals.

- The technical approaches that have also been proposed include preserving ecosystems and biodiversity; enhancing the sustainable development of land, water, air and biological resources and how we utilization them; applying resource regeneration; increasing and expanding the use of renewable energy resources; and expanding preventive health care.

- Many efforts have focused on environmental stewardship. Life cycle assessment is a holistic way of examining the environmental impact of a product or process, by considering all resource input and waste emissions, at all phases of the life cycle of a product or process, and their impacts on the environment 
(Curran, 2012; Sørensen, 2011). Biomimicry has been proposed as a route to sustainable development, by taking advantage of ecology and nature management principles to guide the development of innovations and achieve a more resilient society. Industrial ecology was put forward as a means of allowing ecological principles, like using cyclic rather than once-through processes, to guide industrial development (Zvolinschi et al., 2007; Dincer and Rosen, 2013).

To help in disseminating and sharing the growing amount of sustainable development activity by researchers, practitioners and decision makers throughout the world, especially related to new research developments, journals focusing on sustainable development and sustainability are needed. Sustainable development research is at times reported in journals dedicated to the application field, and at other times reported in journals dedicated to sustainable development and its many multidisciplinary aspects. The latter need becomes increasingly important as the field of sustainable development grows and expands, making it progressively vital for meaningful and productive interactions among sustainable development researchers in varying fields (e.g., societal, environmental, technical, health). The journal in which this article is published, the European Journal of Sustainable Development Research, is part of the effort to meet this need, in that it was launched to help meet the growing need for publications that foster fruitful discussions between researchers from different fields, and permit the exchange of cross-fertilizing ideas.

\section{CASE STUDY}

An interesting case study regarding sustainable development is embodied in the Red Sea-Dead Sea canal project, which aims to satisfy human demand for more resources by trying to increase the Dead Sea resources supply. The present author recently Rosen and Abu Rukah (2011) investigated this project and its interface with sustainable development. The Dead Sea and its unique environment are degrading due to anthropogenic activity affecting its water balance. Since the start of the 20th century, the Dead Sea level dropped by more than 40 meters, reaching 430 meters below mean sea level in 2016 (see Table 1).

Table 1. Variation in Dead Sea water level elevation since 1930

\begin{tabular}{lc}
\hline Date & Water level below sea level (m) \\
\hline 1930 & 390 \\
\hline 1980 & 400 \\
\hline 1990 & 407 \\
\hline 2000 & 414 \\
\hline 2010 & 423 \\
\hline 2016 & 430 \\
\hline
\end{tabular}

Annually, $0.1 \mathrm{~m}$ of salt is accumulating at the bottom, and the volume is decreasing by 700 million cubic meters, leaving an annual freshwater deficit of about 850 million cubic meters. The negative water balance is mainly due to the diversion of water from its catchments area by Israel, Jordan, Syria and Lebanon, as well as industrial activity in the southern basin of the Dead Sea.

In 2002 Israel and Jordan jointly announced interest in stopping the water level decline and deterioration by constructing a Red Sea-Dead Sea canal to pipe water from the Red Sea to the Dead Sea. The project represents an important plan developed to avoid the loss of the Dead Sea and to desalinate sea water as well as to generate electricity for Jordan, the Palestinian National Authority and Israel. The proposed desalination plant with an annual capacity of 850 million cubic meters of fresh water that will utilize the 400 meter elevation difference between the Seas. In 2005 Israel, Jordan and the Palestinian National Authority submitted to the World Bank terms of reference for a "Feasibility Study - Environmental, Technical and Economic, and Environmental and Social Assessment," which describes the environmental concerns associated with the project. The World Bank announced that steps towards the realization of the feasibility study would take place in 2007 . The project, with continual modifications of details, now seems ready to proceed, with Israel and Jordan advancing $\$ 800$ million US for the project within the last year (UN, 2015).

In addition to avoiding the loss of the Dead Sea and generating electricity, the desalination of seawater is a major objective of the project. The following major tasks have been defined (Beyth, 2007):

- Desalinate sea water (2000 million cubic meters) to produce 800-850 million cubic meters of fresh water with 20 to $300 \mathrm{mg} / 1$ total dissolved salts, annually.

- Restore the Dead Sea level to around 400 meters below sea level.

- Counter the accelerating degradation of the Dead Sea and the surrounding environment and restore it to a previous historical level.

- Supply a sustainable source of potable water for Jordan, the Palestinian National Authority and Israel. 


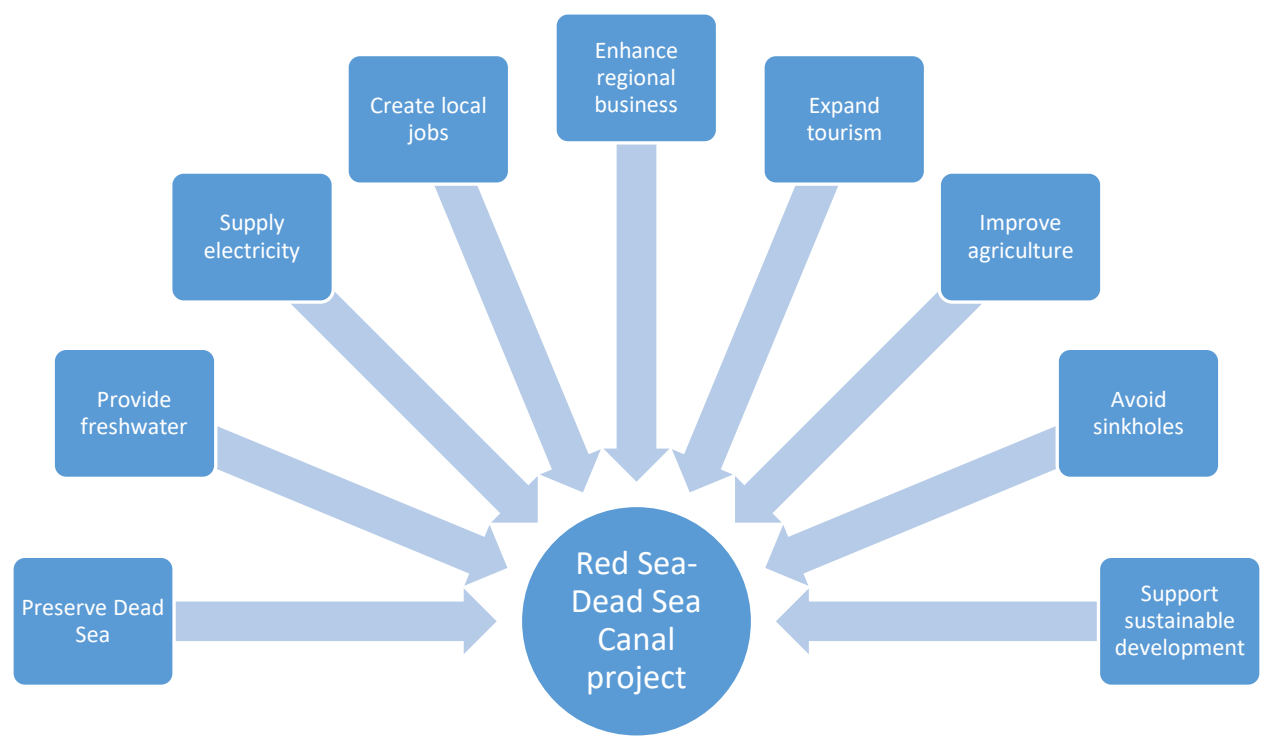

Figure 11. Benefits of Red Sea-Dead Sea canal project, supporting its contribution to numerous elements of sustainable development

- Exploit the head difference between the Red Sea and the Dead Sea (about $400 \mathrm{~m}$ ) to produce hydroelectric power for operating the desalination plant using the process of reverse osmosis and to derive additional energy benefits.

Although there are environmental concerns regarding the project, it nonetheless is viewed as providing significant environmental benefits. Some of the main positive impacts of the project include: preserving the Dead Sea as a historical and valuable site, providing water to augment the supply to all partners, providing electricity, improving the quality of life in the project area, job creation for the local populations, improved regional business prospects, enhancing tourism, improving agriculture, and preventing sinkhole formation.

The Red-Mediterranean-Dead Seas Canal project has been shown to be the type of large project that may contribute significantly to sustainable development and, more generally, to the sustainability of human activity. The Red-Mediterranean-Dead Seas Canal project contributes to sustainable development by supporting energy sustainable development, the sustainable development of an important resource (fresh water), avoidance of environmental problems through the restoration of the Dead Sea, economic development and, potentially, regional political stability. The large quantities of desalinated water to be derived from the project are of particular significance to the partners in the region. Concerns have been identified that need to be addressed, such as the stratification and dilution of the Dead Sea water and changes in the biological environment of the upper water mass. Nonetheless, the project thereby addresses simultaneously social, economic and environmental objectives in a complementary and interrelated manner, and balances these societal objectives, making appropriate trade-offs as necessary.

The benefits of Red Sea-Dead Sea canal project, which in many ways drive its contribution to numerous elements of sustainable development, are summarized in Figure 11.

\section{CONCLUSIONS}

Progress and advances in the field of sustainable development in general, and especially in sustainable development technology, systems and methods, and improved decision making and policy development have been made in recent years and will likely continue to be made at an increasing pace in the future. Scholarly journals will help disseminate research on sustainable development and sustainable development and exchange ideas, and thereby contribute the growth of the discipline and its applications.

Sustainable development requires efforts from stakeholders, which essentially constitute all people and the groupings possible of them. This idea is illustrated in Figure 12, in which it is shown that sustainable development requires, starting with the smallest constituency and expanding to the largest, the involvement and actions of individual people, followed by industry, which is a type of collective of people. Then, the actions of communities, which include the local population and industry, are needed. More broadly, the actions and support of cities and regions are needed, often with political incentives and actions, as well as the actions and supports of countries, 


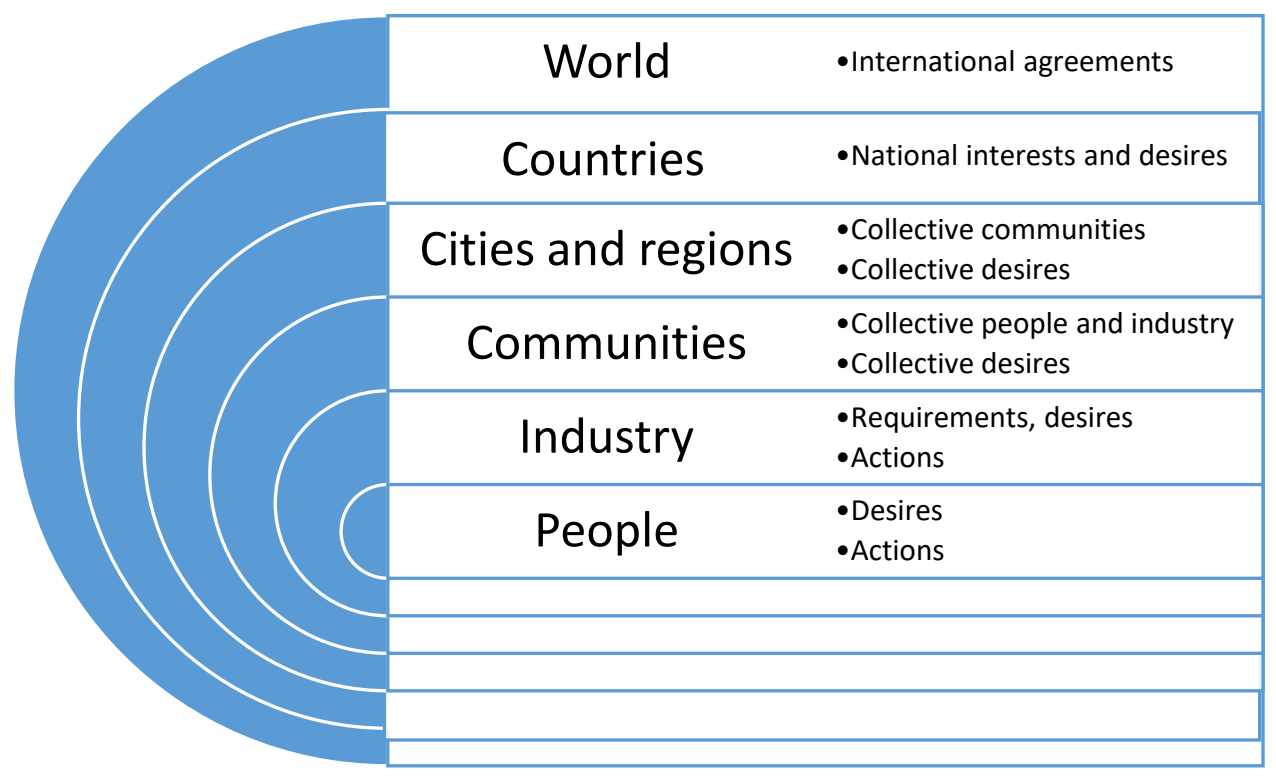

Figure 12. Illustration of how sustainable development requires efforts from stakeholders, ranging from individuals and communities to countries and the global community

ideally with national goals for sustainable development. Finally, the support of all countries of the world is needed for sustainable development, given the multinational nature of many factors like climate change. This is typically managed through international agreements, like the 2030 Agenda for Sustainable Development of the United Nations, discussed earlier.

\section{ACKNOWLEDGEMENTS}

The contributions of numerous colleagues and students through dialogues and debates about sustainable development are acknowledged, as they significantly influenced the content and presentation of this article.

\section{REFERENCES}

Adams, R., Jeanrenaud, S., Bessant, J., Denyer, D. and Overy, P. (2016). Sustainability-oriented Innovation: A Systematic Review. International Journal of Management Reviews, 18, pp. 180-205.

Mansoori, A., Nader Enayati, G. and Barnie Agyarko, L. (2016). Energy: Sources, Utilization, Legislation, Sustainability, Illinois as Model State. World Scientific, Singapore.

Anderson, M.W., Teisl, M.F. and Noblet, C.L. (2016). Whose values count: Is a theory of social choice for sustainability science possible? Sustainability Science, 11(3), pp. 373-383.

Beyth, M. (2007). The Red Sea and Mediterranean-Dead Sea canal project. Desalination 214, pp. 364-370.

Curran, M.A. (Ed.) (2012). Life Cycle Assessment Handbook: A Guide for Environmentally Sustainable Products, Wiley, Hoboken, NJ and Scrivener Publishing, Salem, MA.

Dewulf, H., Van Langenhove, H., Mulder, J., van den Berg, M.M.D., van der Kooi, H.J. and de Swaan Arons, J. (2000). Illustrations towards quantifying the sustainability of technology. Green Chemistry 2, pp. 108-114.

Dincer, I. and Rosen, M.A. (2013). Exergy: Energy, Environment and Sustainable Development, 2d ed., Elsevier, Oxford, UK.

Evans, A., Strezov, V. and Evans, T.J. (2009). Assessment of sustainability indicators for renewable energy technologies. Renewable and Sustainable Energy Reviews, 13, pp. 1082-1088.

Frangopoulos, C.A. and Keramioti, D.E. (2010). Multi-criteria evaluation of energy systems with sustainability considerations. Entropy, 12, pp. 1006-1020.

Gnanapragasam, N.V., Reddy, B.V. and Rosen, M.A. (2011). Sustainability of an Energy Conversion System in Canada Involving Large-Scale Integrated Hydrogen Production Using Solid Fuels. International Journal of Energy and Environment, 2(1), pp. 1-38.

Gomez-Echeverri, L., Johansson, T.B., Nakicenovic, N. and Patwardhan, A. (Eds.), (2012). Global Energy Assessment: Toward a Sustainable Future, International Institute for Applied Systems Analysis, Vienna, and Cambridge University Press, Cambridge. 
Hacatoglu, K., Dincer, I. and Rosen, M.A. (2015). A New Model to Assess the Environmental Impact and Sustainability of Energy Systems. Journal of Cleaner Production, 103, pp. 211-218

Hacatoglu, K., Dincer, I. and Rosen, M.A. (2016). Sustainability Assessment of a Wind-Hydrogen Energy System: Assessment Using a Novel Index and Comparison to a Conventional Gas-Fired System. International Journal of Hydrogen Energy, 41(19), pp. 8376-8385.

Khalid, F., Dincer, I. and Rosen, M.A. (2015). Development and Analysis of Sustainable Energy Systems for Building HVAC Applications. Applied Thermal Engineering, 87, pp. 389-401.

Krajacic, G., Duic, N. and Rosen, M.A. (2015). Sustainable Development of Energy, Water and Environment Systems. Energy Conversion and Management, 104, pp. 1-7.

Nazzal, Y., Abuamarah, B.A., Kishawy, H.A. and Rosen, M.A. (2013). Considering Environmental Sustainability as a Tool for Manufacturing Decision Making and Future Development. Research Journal of Environmental and Earth Sciences, 5(4), pp. 193-200.

Rosen, M.A. (2013). Engineering and Sustainability: Attitudes and Actions. Sustainability, 5(1), pp.372-386.

Rosen, M.A. and Abu Rukah, Y. (2011). A Pragmatic Approach for Sustainable Development of the RedMediterranean-Dead Seas Canal Project: A Case Study. Int. J. Ecology \& Development, 19(S11), pp. 63-75.

Russell-Smith, S.V., Lepech, M.D., Fruchter, R. and Meyer, Y.B. (2015). Sustainable target value design: integrating life cycle assessment and target value design to improve building energy and environmental performance. $J$. Clean. Prod., 88, pp. 43-51.

Sørensen, B. (2011). Life-Cycle Analysis of Energy Systems: From Methodology to Applications. Cambridge, UK: Royal Society of Chemistry.

UN. (2015). Resolution adopted by the General Assembly on 25 September 2015. A/RES/70/1. Seventieth session. United Nations.

Zijp, M.C., Heijungs, R., van der Voet, E., van de Meent, D., Huijbregts, M.A.J., Hollander, A. and Posthuma, L. (2015). An Identification Key for Selecting Methods for Sustainability Assessments. Sustainability, 7, 2490-2512.

Zvolinschi, A., Kjelstrup, S., Bolland, O. and van der Kooi, H.J. (2007). Exergy sustainability indicators as a tool in industrial ecology. Journal of Industrial Ecology, 11, pp. 85-98. 